\title{
Avaliação dos perfis minerais séricos, urinários e sedimentares de ovinos recebendo dieta calculogênica
}

\author{
[Evaluation of mineral profile in serum, urine and sediment of sheep \\ receiving calculogenic diet] \\ T.A. Maciel ${ }^{1}$, N.L. Júnior ${ }^{2}$, V.V. Araújo², A.B. Silva Filho², D.L.S.Gomes ${ }^{2}$, A.M.S. Barbosa², \\ C.C. Farias ${ }^{3}$, A.L.R. Magalhães ${ }^{2}$, M.J.M. Lima ${ }^{4}$, S.A.X. Melo ${ }^{4}$, D. Oliveira ${ }^{2} *$ \\ ${ }^{1}$ Programa de pós-graduação - Universidade Federal Rural de Pernambuco - UFRPE - Unidade Acadêmica de \\ Garanhuns - UAG - Garanhuns, PE \\ ${ }^{2}$ Universidade Federal Rural de Pernambuco - UFRPE - Unidade Acadêmica de Garanhuns - UAG -Garanhuns, PE \\ ${ }^{3}$ Universidade Federal de Pernambuco - Recife, PE \\ ${ }^{4}$ Universidade Federal Rural de Pernambuco - UFRPE - Recife, PE
}

\section{RESUMO}

A urolitíase obstrutiva em pequenos ruminantes é uma doença metabólica de etiologia multifatorial com distribuição mundial. A elevação da concentração urinária de solutos, minerais ionizados (cristaloides) que formam cristais insolúveis é citada por alguns autores como o fator mais importante. Assim, o conhecimento do perfil mineral dos animais submetidos a dietas calculogênicas e a composição química dos urólitos tornam-se ferramentas eficazes na prevenção da doença. Neste estudo, foram utilizados 14 ovinos hígidos, machos (não castrados), da raça Santa Inês, com idade aproximada de 90 dias, distribuídos em dois grupos (G1 - sem vitamina C e G2 - com vitamina C) e alimentados com dieta calculogênica. A análise dos perfis minerais, séricos e urinários revelou completo desbalanceamento na relação entre concentrações de cálcio, fósforo e magnésio, havendo elevação expressiva do fósforo e do magnésio e diminuição substancial do cálcio. Com isso, a análise bioquímica dos urólitos demonstrou que o cálcio esteve presente em $50 \%$ das amostras analisadas.

Palavras-chave: doença de ovinos, mineral, trato urinário, urolitíase

\section{ABSTRACT}

Urolithiasis in small ruminants is a metabolic disease of multifactorial etiology with worldwide distribution. Increased urinary concentration of solutes, ionized minerals (crystalloid) that form insoluble crystals is cited by some authors as the most important factor. Thus, knowledge of mineral profile of the animals fed calculogenic diets and chemical composition of uroliths becomes an effective tool in preventing the disease. In this study, we used 14 healthy, male, non-neutered sheep, of the Santa Ines breed, aged approximately 90 days, divided into two groups (G1-without vitamin C and G2-with vitamin C) fed calculogenic diet. Analysis of mineral profiles in serum and urine revealed complete imbalance in the relationship between concentrations of calcium, phosphorus and magnesium, with significant increase of phosphorus and magnesium and substantial reduction of calcium. Thus, biochemical analysis of uroliths showed that calcium was present in $50 \%$ of samples.

Keywords: Sheep disease, mineral, urinary tract, urolithiasis

\section{INTRODUÇÃO}

A urolitíase obstrutiva em pequenos ruminantes é uma enfermidade relatada em diferentes países

Recebido em 13 de abril 2015

Aceito em 18 de fevereiro de 2016

*Autor para correspondência (corresponding author)

E-mail: danisjc6@yahoo.com.br de todos os continentes (Guimarães et al., 2007; Riet-Correa et al., 2008; Vinodhkumar et al., 2010). Em regiões áridas, onde o consumo de água é fator limitante, a incidência é maior. Embora apresente caráter esporádico, pode 
ocorrer em forma de surtos ou endêmica, refletindo a importância da dieta e do manejo na patogênese da enfermidade para o rebanho (Van Mitre e Divers, 2006).

O rebanho ovino brasileiro em 1974 somava 18,87 milhões de cabeças, revelando-se muito expressivo no cenário mundial, com recorde registrado em 1991 com 20,12 milhões. Embora tenha havido uma diminuição significativa nos anos seguintes, uma recuperação expressiva tem sido observada desde 2003, impulsionada pela preferência e pelo consumo crescentes da carne, refletindo em um rebanho de 14,16 e 16,78 milhões para os anos de 2006 e 2012, respectivamente ( Censo..., 2006; Zen et al., 2014). Destaque especial é dado à região Nordeste, por apresentar forte tradição na criação desses animais, principalmente de raças nativas, e por ser detentora do maior rebanho nacional, aproximadamente $67,8 \%$ em 2006 e 56,7\% em 2010 (Berro, 2006; Censo..., 2006; Produção..., 2010; Zen et al., 2014). Esse é um fato relevante ao se considerar que as condições climáticas na região predispõem o desenvolvimento da doença.

Urolitíase é uma doença metabólica de etiologia complexa e multifatorial, caracterizada pela formação de urólitos no sistema urinário. Afonso e Guaraná (2008) referem-se ao surgimento de condições que favorecem a elevação da concentração urinária de solutos, minerais ionizados (cristaloides) que formam cristais insolúveis, como o fator mais importante.

A urina é uma solução saturada com grande quantidade de solutos, incluindo os íons calculogênicos, contudo a existência de elementos em sua composição que atuam como inibidores intrínsecos da cristalização, como mucopolissacarídeos (coloides protetores), íons e ácidos orgânicos, impede que essa condição isolada seja responsável pela formação dos urólitos. Apenas quando a urina torna-se saturada e os cristaloides presentes excedem a capacidade protetora de inibir a cristalização inicia-se a formação do urólito, que tem como base para sua formação um núcleo composto por um grupo de células epiteliais descamadas ou tecido necrótico, resultante de infecções e inflamações locais (Radostits, 2007).

Os melhores resultados para manter a integridade reprodutiva são obtidos com a prevenção da doença, antes que se inicie a formação do cálculo. Nesse sentido, conhecer os perfis minerais séricos, urinários e a composição química dos urólitos auxilia corrigir todos os possíveis fatores que podem estar relacionados à sua formação. Entre os métodos de prevenção, a acidificação urinária é citada como alternativa eficiente (Ferreira et al., 2011; Ferreira, 2013).

Esta pesquisa teve por objetivo avaliar o potencial de acidificação urinária da vitamina $\mathrm{C}$ e seu efeito como prevenção da urolitíase obstrutiva em ovinos da raça Santa Inês submetidos a dietas calculogênicas, bem como traçar o perfil mineral para predizer a evolução da doença.

\section{MATERIAL E MÉTODOS}

A metodologia adotada para o desenvolvimento da presente pesquisa foi aprovada pela Comissão de Ética no Uso de Animais (CEUA) da Universidade Federal Rural de Pernambuco (UFRPE), Recife-PE, sob protocolo de número 13726/2012-97.

Foram utilizados 14 ovinos hígidos, machos (não castrados), da raça Santa Inês, com idade aproximada de 90 dias e peso médio de $23,53 \pm 4,45$. Antes do início do experimento, foram submetidos à realização do exame parasitológico de fezes, ao controle de endoparasitas com sulfaquinoxalina e closantel sódico oral (Sulfaquinoxalina ${ }^{\circledR}$ Vansil e Diantel ${ }^{\circledR}$ $10 \%$ ) e vacinados contra clostridioses (Poli-Star ${ }^{\circledR}$ Valle).

Seguiu-se a distribuição aleatória em dois grupos experimentais: grupo 1 (sem vitamina $C, n=7$ ) e grupo 2 (com suplementação de vitamina $\mathrm{C}$, preparada em laboatório de manipulação, 1g/animal/dia, n=7). Na aclimatação, antes do início do experimento, os animais receberam dieta balanceada e, posteriormente, aumento na proporção concentrado/volumoso de forma gradativa, por período de 15 dias, para adaptação da microflora ruminal.

Os animais foram confinados em baias de alvenaria para pequenos ruminantes da Unidade Acadêmica de Garanhuns (UAG), UFRPE, onde ficaram sob condições iguais de temperatura, umidade do ar e luminosidade, em baias 
individuais de 2,0m x 1,0m de alvenaria, durante todo o período experimental.

Foi oferecida água ad libitum oriunda de fonte natural, fornecida por meio de baldes plásticos para mensuração do consumo diário, bem como alimentação por 90 dias com ração com níveis de $\mathrm{Ca} / \mathrm{P}$ 1:2 e relação volumoso/concentrado de 30:70 (Tab. 1). Aos animais do grupo 2 foi administrada uma cápsula de $1 \mathrm{~g}$ de vitamina $\mathrm{C}$ por dia, via oral. Após os 90 dias, a relação $\mathrm{Ca} / \mathrm{P}$ foi modificada para 1:3 e os animais passaram a receber a nova dieta por 45 dias. A ração total foi fornecida de forma fracionada em dois momentos (manhã/tarde), em horários fixos, em cochos de plástico com dimensões de $50 \times 20 \times 30 \mathrm{~cm}$, e as sobras eram pesadas diariamente para determinação do consumo. O período total de confinamento, cerca de 119 dias, foi estabelecido neste experimento para assegurar tempo e condições suficientes para formação dos urólitos e desenvolvimento do quadro de urolitíase obstrutiva. Para a segurança experimental, os ingredientes da ração total foram submetidos à análise bromatológica (Tab. 2) e a água, à análise de sua composição química (Tab. 3) pelo Laboratório de Nutrição Animal (Lana), da UAG/UFRPE.

Tabela 1. Composição das dietas experimentais

\begin{tabular}{cc}
\hline Ingrediente & $\begin{array}{c}\text { Dieta desbalanceada (g/kg de MS) } \\
\text { Relação Ca/P (desbalanceada) }\end{array}$ \\
\hline Feno de tifton 85 & 300,00 \\
Milho moído & 560,70 \\
Farelo de soja & 96,00 \\
Fosfato de sódio dibásico anidro & 22,00 \\
Suplemento mineral & 15,00 \\
\hline & Composição química \\
\hline Matéria seca (g/kg de MS) & 860,94 \\
Proteína bruta (g/kg de MS) & 121,36 \\
Energia metabolizável (kcal) & 2774 \\
Extrato etéreo (g/kg de MS) & 45,58 \\
Cálcio (g/kg de MS) & 4,16 \\
Fósforo (g/kg de MS) & 8,38 \\
\hline
\end{tabular}

Tabela 2. Composição nutricional dos ingredientes das dietas experimentais

\begin{tabular}{ccccc}
\hline Item & Feno de tifton & Milho moído & Farelo de soja & Fosfato de sódio dibásico \\
\hline Matéria seca & 860,13 & 860,34 & 880,01 & 990,00 \\
Proteína bruta $(\mathrm{g} / \mathrm{kg})$ & 82,90 & 90,00 & 470,08 & - \\
Matéria mineral $(\mathrm{g} / \mathrm{kg})$ & 75,30 & 10,70 & 62,50 & - \\
Extrato etéreo $(\mathrm{g} / \mathrm{kg})$ & 28,50 & 65,39 & 33,40 & - \\
Fósforo $(\mathrm{g} / \mathrm{kg})$ & - & - & - & 230 \\
Sódio $(\mathrm{g} / \mathrm{kg})$ & - & - & - & 16 \\
\hline
\end{tabular}

Tabela 3. Análise química da água

\begin{tabular}{cc}
\hline Variáveis & Valores \\
\hline Condutividade & $0,633 \mathrm{mS} / \mathrm{cm}$ \\
$\mathrm{pH}$ & 5,8 \\
Sólidos totais & $0,532 \mathrm{ppm}$ \\
Cálcio & $6,4 \mathrm{ppm}$ \\
Magnésio & $8,1 \mathrm{ppm}$ \\
Dureza & $42 \mathrm{ppm}$ \\
Cloretos & $7,9 \mathrm{ppm}$ \\
\hline
\end{tabular}

$\mathrm{ppm}=$ partes por milhão; $\mathrm{mS} / \mathrm{cm}=$ milisiemens por centímetro. 
Os animais foram rigorosamente examinados semanalmente, seguindo técnica descrita por Diffay et al. (2005), e avaliados quanto aos achados de hemograma, à análise dos perfis minerais séricos e urinários e à análise da composição química dos urólitos.

Os momentos (M) de coleta de amostras de sangue e urina e a avaliação clínica foram realizados com intervalos de sete dias, sendo o M0 imediatamente antes do início do tratamento com dieta calculogênica e fornecimento da vitamina C, o M1 sete dias após e o M2 14 dias depois, totalizando 17 momentos (M16 - 119 dias de confinamento). Todas as coletas de urina e sangue foram realizadas antes do fornecimento da alimentação, pela manhã, entre seis e oito horas, com os ovinos contidos manualmente, com o uso de cabresto e em estação para minimizar o estresse.

As coletas de sangue foram realizadas por venopunção jugular após antissepsia local com álcool a $70^{\circ}$. A determinação do perfil hematológico foi realizada em dois momentos: o primeiro, previamente ao início do experimento (M0), e o segundo, imediatamente após constatação da obstrução ou período final do tempo experimental (M16). Foi coletada a alíquota de $4 \mathrm{~mL}$ de sangue, usando-se tubos a vácuo com EDTA-sódico e com agulha $25 \times 8 \mathrm{~mm}$ (BD Vacutainer ${ }^{\circledR}$, BD Medical, Curitiba-PR, Brasil).

Para determinação do perfil bioquímico mineral sanguíneo, foram realizadas coletas semanais até o estabelecimento da urolitíase obstrutiva ou período final do tempo experimental. Alíquotas de $8 \mathrm{~mL}$ de sangue foram coletadas em tubos a vácuo sem anticoagulante. $\mathrm{O}$ soro sanguíneo foi separado, armazenado em alíquotas de $1 \mathrm{~mL}$ (Eppendorf do Brasil Ltda., São Paulo-SP, Brasil), e congelado a $-20^{\circ} \mathrm{C}$, para determinação dos minerais cálcio ( $\mathrm{Ca}$ Arsenazo Liquiform), fósforo (Fósforo UV Liquiform), magnésio (Magnésio), sódio (Sódio Enzimático), cloro (Cloretos Liquiform) e potássio (Potássio Enzimático), utilizando-se como calibrador Calibra $\mathrm{H}$ e como controle Qualitrol 2H, por meio de kits da Lab-test Diagnóstica, Lagoa Santa, MG, em analisador bioquímico automático (Labmax 240) do Laboratório de Análises Clínicas do HOVET/UFRPE e dos íons sódio $\left(\mathrm{Na}^{+}\right)$, potássio $\left(\mathrm{K}^{+}\right)$e cloreto $\left(\mathrm{Cl}^{-}\right)$, por meio do analisador de íons (Roche).

Provocou-se a micção interrompendo-se a respiração dos animais pela oclusão das narinas durante 10 a 20 segundos (Garcia-Navarro, 2005). Amostras de, no mínimo, $10 \mathrm{~mL}$ de urina de cada animal dos dois grupos por micção natural ou forçada foram coletadas semanalmente, até o aparecimento dos primeiros sinais clínicos da urolitíase obstrutiva. As amostras de urina foram acondicionadas em frascos estéreis (coletor universal, 50mL) e encaminhadas imediatamente ao Laboratório Clínico da Clínica de Bovinos de Garanhuns (CBG/UFRPE) para realização da urinálise, a fim de evitar degeneração dos elementos celulares e proliferação bacteriana.

No exame físico da urina foram avaliados: volume, coloração, odor, aspecto e densidade por refratometria (Quimis, Diadema, SP). O exame químico foi realizado por meio de fitas reagentes para urinálise (Uriquest, Lab-test Diagnóstica, Lagoa Santa, MG). Para exame do sedimento urinário, foi utilizada a técnica descrita por Valenciano e Cowell (2014).

Para mensuração das concentrações de minerais (cálcio, fósforo, magnésio, sódio, potássio e cloro) excretados na urina, foram utilizados os kits da Lab-test Diagnóstica, Lagoa Santa, MG, descritos anteriormente. Para tanto, após centrifugação, quatro alíquotas contendo $1 \mathrm{~mL}$ de urina foram congeladas e armazenadas em Eppendorfs.

A análise da composição química dos urólitos foi realizada em difratômetro de raios-x PW 3040/60 da PANalytical com goniômetro PW 3050/60 e com tubo de raios-x de anodo de cobre $(\mathrm{K} \alpha 1$ $\lambda=1,54 \AA$ ), pela técnica da difração de raios-x, descrita por Betejtin (1977) e Milovsky e Kononov (1985), e realizada no Laboratório de Mineralogia, do Departamento de Geologia da Universidade Federal de Pernambuco.

Foi utilizada a calibração com voltagem $40 \mathrm{hv}$, corrente $30 \mathrm{~mA}$, varredura $2^{\circ}-10^{\circ}$ a $70^{\circ}$ e tamanho de grãos $0,02 \mathrm{~m}$. A identificação foi feita por meio de comparação com padrão difratométrico obtido com fichas do banco de dados da ASTM-Departamento de MecânicaCTG/UFPE. 
A análise estatística dos valores obtidos das análises laboratoriais dos grupos foi feita ao longo dos momentos de observação (em intervalos de sete dias) até o desenvolvimento da urolitíase obstrutiva em todos os animais do grupo 1 ou finalização do tempo experimental preestabelecido (119 dias). Comparando-as entre si, as variáveis foram submetidas a modelos paramétricos, empregando-se a análise de variância, com os testes das hipóteses. Procurouse verificar se houve interação entre grupo e momento, e, no caso de a existência ser significativa, a análise foi complementada, observando-se o efeito de momento em cada grupo e o efeito de grupo em cada momento. Não existindo, foi calculado o efeito de grupo no conjunto dos momentos e o efeito de momento no conjunto dos grupos. As estatísticas $\mathrm{F}$ calculadas foram consideradas significativas quando $\mathrm{P}<0,05$, e os contrastes entre as médias foram realizados pelo método de Tukey, calculando-se a diferença mínima significativa (dms) para alfa igual a 0,05 (Curi, 1997).

\section{RESULTADOS E DISCUSSÃO}

Os valores médios das concentrações dos minerais nos diferentes grupos e momentos experimentais são mostrados nas Tab. 4 e 5 . Ao se analisarem as concentrações séricas de cálcio, fósforo e magnésio, verifica-se um completo desbalanceamento na relação entre esses minerais, havendo elevação expressiva do fósforo e do magnésio e diminuição substancial do cálcio. Valores de relação $\mathrm{Ca} / \mathrm{P}$ dentro do desejável foram obtidos apenas em M0 e M1 $(1,37$ e $1,43 \mathrm{mg} / \mathrm{dL})$, imediatamente antes e uma semana após o fornecimento da dieta calculogênica. Passou a haver decréscimo das proporções em M2 e M3 e inversão da relação, atingindo níveis críticos a partir de M4, com menor proporção registrada em M14 $(0,32 \mathrm{mg} / \mathrm{dL})$, revelando o efeito significativo que a dieta com desbalanço nos níveis desses minerais tem para o metabolismo quando mantida por mais de 21 dias (Tab. 4).
VinodhKumar et al. (2010) e Morais (2012) encontraram em suas pesquisas comportamento semelhante. $O$ desequilíbrio na alimentação oferecida aos animais, especialmente quanto aos teores de cálcio, fósforo e magnésio, é tido como uma das principais causas de urolitíase obstrutiva, por promover alterações no $\mathrm{pH}$ urinário (Silva, 1997).

O cálcio total sérico revelou-se inferior ao descrito por Kaneko et al., (2008), de 11,5 a $12,8 \mathrm{mg} / \mathrm{dL}$ para a espécie ovina. Apresentou decréscimo progressivo a partir de M8, com menor concentração registrada em M15 $(5,83 \mathrm{mg} / \mathrm{dL})$. As concentrações séricas e de excreção apresentaram proporção de 1:1 apenas em M0 $(9,55 \mathrm{mg} / \mathrm{dL})$; a partir de M1, a taxa de excreção urinária foi drasticamente reduzida, com padrão mantido ao longo dos momentos e valores entre 2,09 e 7,42mg/dL. Takagi e Block (1991) atestam que dietas acidogênicas aumentam a excreção urinária de cálcio e diminuem sua retenção, fato não observado na presente pesquisa, o que sugere que mecanismos de reabsorção desse mineral estimulada pelo paratormônio e pela vitamina $\mathrm{D}$ entrem em ação diante de baixas concentrações plasmáticas (Swenson e Reece, 1996). Já o cálcio ionizável manteve-se estável até M9, com posterior decréscimo e manutenção das concentrações entre 0,52 e $0,69 \mathrm{mg} / \mathrm{dL}$, demonstrando que a forma ionizável apresenta maior estabilidade ao longo dos momentos e que sofre alteração apenas quando as concentrações de cálcio total permanecem baixas por longos períodos.

O fósforo sérico, por sua vez, apresentou elevação significativa a partir de M3, mantendose elevado até M16, com pico registrado em M14 $(18,70 \mathrm{mg} / \mathrm{dL})$, sendo proporcional à taxa de excreção, que se elevou a partir de M2 e com pico em M14 (19,73mg/dL). De acordo com Belknap e Pugh (2005) e Riet-Correa et al. (2008), o desequilíbrio Ca:P resulta em elevada excreção de fósforo pela urina, sendo importante fator para a gênese dos urólitos. 
Maciel et al.

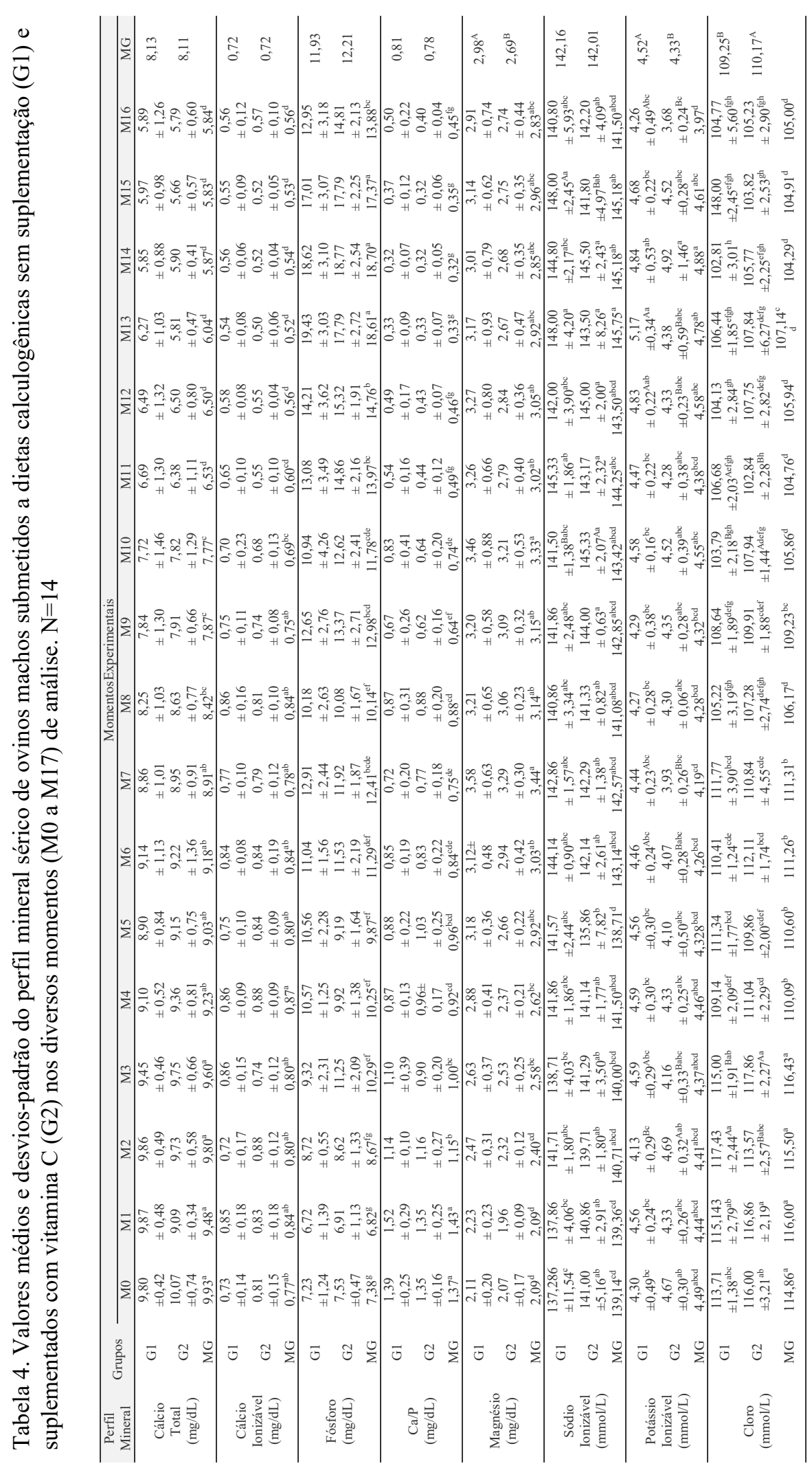




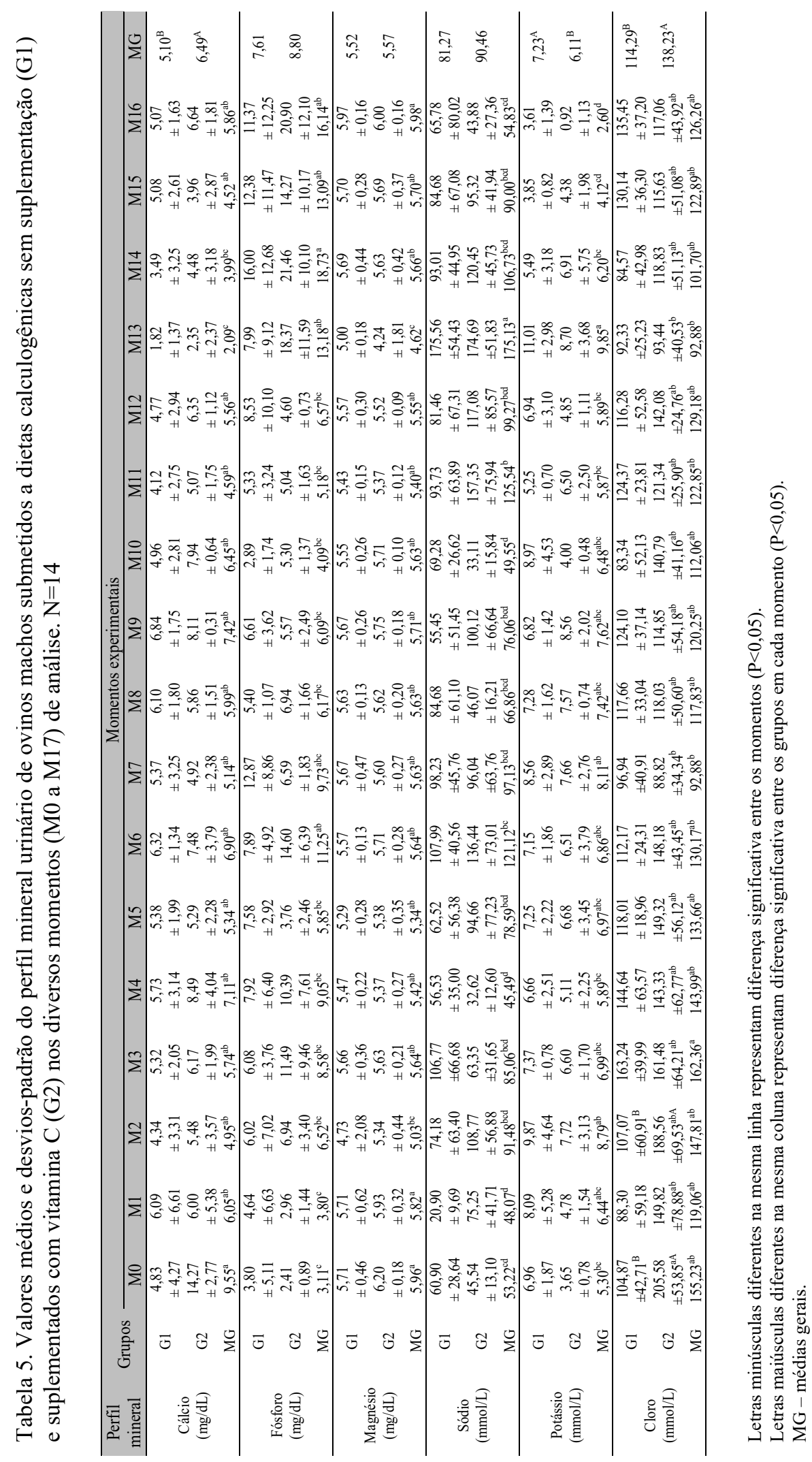


Apesar da baixa concentração urinária de cálcio, a análise da composição química dos urólitos (Tab. 6) demonstrou que esse mineral estava presente em $50 \%$ das amostras. No entanto, não foi evidenciada a presença de fósforo, diferentemente do relatado por Riet-Correa et al. (2008), que afirmaram que animais alimentados com grãos apresentam cálculos formados principalmente por fósforo (estruvita). Prevalência de cálcio na composição química dos urólitos também foi também relatada por Guimarães et al. (2012) e Ferreira (2013). Segundo Aquino Neto et al. (2007), a urina dos ruminantes é alcalina, o que torna o fósforo insolúvel, precipitando-o e formando cristais com o cálcio e o magnésio.

Tabela 6. Composição (\%) dos urólitos de ovinos machos $\mathrm{G} 1(\mathrm{~N}=3)$ e $\mathrm{G} 2(\mathrm{~N}=2) . \mathrm{N}=5^{*}$

\begin{tabular}{ccc}
\hline Substâncias & $\mathrm{G} 1$ & $\mathrm{G} 2$ \\
\hline $\begin{array}{c}\text { Tartrato de cálcio }\left(\mathrm{C}_{4} \mathrm{H}_{4} \mathrm{CaO}_{6}-\right. \\
\left.\mathrm{H}_{2} \mathrm{O}\right)\end{array}$ & 25 & \\
$\begin{array}{c}\text { Citrato de cálcio hidratado } \\
\left(\mathrm{CaH}_{7} \mathrm{NO}_{3}\right)\end{array}$ & 25 & \\
$\begin{array}{c}\text { Oxalato de sódio hidratado } \\
\left(\mathrm{C}_{2} \mathrm{HNaO}_{9}-\mathrm{H}_{2} \mathrm{O}\right)\end{array}$ & 25 & \\
$\begin{array}{c}\text { Oxalato de potássio hidratado } \\
\left(\mathrm{C}_{4} \mathrm{H}_{3} \mathrm{KO}_{8}-2 \mathrm{H}_{2} \mathrm{O}\right)\end{array}$ & & 25 \\
\hline
\end{tabular}

Análises realizadas no Departamento de Mecânica CTG/UFPE.

*Devido ao volume insuficiente, não foi possível realização da análise em uma das amostras.

As concentrações séricas de magnésio mostraram-se superiores aos padrões estabelecidos por Kaneko et al. (2008) e Smith e Sherman (2009) a partir do M5, com elevação progressiva até M10 $(3,33 \mathrm{mg} / \mathrm{dL})$, e, embora tenha apresentado decréscimo até M16 $(2,83 \mathrm{mg} / \mathrm{dL})$, permaneceu com média no limite superior para a espécie. Evidenciou-se que as taxas de excreção desse elemento se mostraram superiores aos níveis séricos, com valores compreendidos entre 4,62 e 5,98mg/dL.

Em resultado da dieta desbalanceada, os elevados níveis de magnésio e fósforo e os baixos níveis de cálcio observados aumentam a possibilidade de formação de urólitos devido à retenção renal do magnésio e ao aumento na excreção do fósforo, elevando a concentração urinária (Riet-Correa, 2004; Riet-Correa et al., 2008). Segundo esses autores, o uso de ração desbalanceada está entre os fatores responsáveis pelo aparecimento de urolitíase no semiárido nordestino.

Elevação com pequenas oscilações foi evidenciada na concentração de sódio ao longo dos momentos, com aumento significativo e pico registrado em M13 (145,75mmol/L). As médias obtidas no presente estudo assemelham-se às descritas por Ferreira (2013). As taxas de excreção comportaram-se de modo semelhante, com valores variando de 45,49 a 175,13mmol/L.
As concentrações desse mineral mostraram-se importantes no presente estudo, uma vez que $25 \%$ dos urólitos analisados apresentaram esse mineral em sua composição.

O potássio apresentou pequenas oscilações ao longo dos momentos, com concentrações aproximadas de $4 \mathrm{mmol} / \mathrm{L}$ e pico de $4,88 \mathrm{mmol} / \mathrm{L}$ em M14, concentrações também observadas por Ferreira (2013). Suas taxas de excreção demonstraram-se superiores às concentrações plasmáticas ao longo dos momentos, a exceção de M15 e M16. Mostrou-se importante na etiologia da doença, fazendo parte da composição química de $25 \%$ dos urólitos analisados.

As maiores concentrações de cloro foram observadas nos primeiros quatro momentos (M0 a M3), com valores compreendidos entre 114,86 e $116,43 \mathrm{mmol} / \mathrm{L}$. Essa substância apresentou diminuição a partir de M4, com pequenas oscilações compreendidas entre 104,29 e $111,31 \mathrm{mmol} / \mathrm{L}$, valores médios também observados por Ferreira (2013) em ovinos com urolitíase. Excetuando-se alguns momentos pontuais, sua taxa de excreção mostrou-se superior às concentrações plasmáticas, com menor valor para os momentos 7 e $13(92,88)$ e maior para M3 $(162,36 \mathrm{mmol} / \mathrm{L})$. Las et al. (2007) também observaram hipercloremia em ovinos alimentados com dieta aniônica. 
Para os animais do presente estudo, a vitamina C não se mostrou eficaz em acidificar e manter o $\mathrm{pH}$ da urina em todos os animais e em todos os momentos do experimento, mesmo sob a alta concentração utilizada (1g/animal/dia). Em contraste, Belknap (2005) sugere doses de apenas 3 a $4 \mathrm{mg} / \mathrm{kg} /$ dia para a obtenção de resultados satisfatórios em acidificar a urina de ovinos. No entanto, a utilização dessa concentração foi experimentada por Ferreira et al. (2011), que administraram 120mg/animal/dia, mas estes demonstraram que, nessa concentração, a vitamina $\mathrm{C}$ não se mostrou eficaz em manter a acidificação urinária.

Sugere-se que, em condições de equilíbrio, a taxa de excreção mineral pode se assemelhar às concentrações plasmáticas. No entanto, constatou-se que o fornecimento de dieta com desbalanço das proporções de minerais constitui o principal fator de risco para formação de urólitos e desenvolvimento da urolitíase obstrutiva. Desequilíbrios metabólicos são desencadeados e mecanismos compensatórios são ativados na busca por manter o equilíbrio das concentrações desses minerais. A diminuição da taxa de excreção do cálcio e o aumento da excreção de fósforo, evidenciadas em todos os animais submetidos a dieta calculogênica, podem exemplificar esse mecanismo.

O delineamento do perfil mineral mostrou-se eficaz em elucidar o comportamento desses elementos em animais submetidos a dietas ricas em concentrado, até a formação dos cálculos e a instalação da doença.

\section{AGRADECIMENTOS}

À Facepe/IBPG, pela concessão da bolsa; ao PRPPG-UAG/UFRPE e à Unesp-Jaboticabal, pelo intercâmbio proporcionado.

\section{REFERÊNCIAS}

AFONSO, J.A.B.; GUARANÁ, E.L.S. Urolitíase em pequenos ruminantes. J. CRMV PE. Vet. Zootec. v.1, p.7-8, 2008.

AQUINO NETO, H.M.; FACURY FILHO, E.J.; CARVALHO, A.U. et al. Urolitíase obstrutiva em ovinos: revisão de literatura. Vet. Foco, v.4, p.191-202, 2007.
BELKNAP, E.B.; PUGH, D.G. Enfermidades do sistema urinário. In: PUGH D.G. (Ed.). Clínica de ovinos e caprinos. São Paulo: Roca, 2005. p.287-310.

BERRO, L. Vale do Capibaribe: uma "terra prometida". BERRO, n.91, p.100-103, 2006.

BETEJTIN, A. Curso de mineralogia. 3.ed. Moscou: Mir Publishers, 1977. 739p.

CENSO AGROPECUÁRIO. [Rio de Janeiro]: IBGE, 2006. 777p. Disponível em: $<$ http://www.ibge.gov.br/home/estatistica/econo $\mathrm{mia} /$ agropecuaria/censoagro/brasil_2006/Brasil_ censoagro2006.pdf $>$. Acessado em: 12 mar. 2014.

CURI, P.R. Metodologia e análise da pesquisa em ciências biológicas. Botucatu: Tipomic, 1997. 263p.

DIFFAY, B.C.; MCKENZIE, D.; WOLF, C.; PUGH, D.G. Abordagem e exame de ovinos e caprinos. In: PUGH D.G. Clínica de ovinos e caprinos. São Paulo: Roca, 2005. p.1-19.

FERREIRA, D.O.L. Modelo experimental de urolitíase em ovinos: estudo clínico, laboratorial e hemogasométrico. 2013. 199f. Tese (doutorado) - Universidade Estadual Paulista, Faculdade de Medicina Veterinária e Zootecnia, Botucatu, SP. Disponível em: $<$ http://base.repositorio.unesp.br/bitstream/handl e/11449/101283/ferreira_dol_dr_botfmvz.pdf?se quence $=1>$. Acessado em: 14 abr. 2014.

FERREIRA, D.O.L.; SANTAROSA, B.P.; MORAES, L.F. et al. Avaliação da acidificação urinária em ovinos com cloreto de amônio, vitamina $\mathrm{C}$ e associação destes. In: CONGRESSO BRASILEIRO DE MEDICINA VETERINÁRIA, 38., 2011, Florianópolis. Anais... Florianópolis: CONBRAVET, 2011. 4p. Disponível em: $<$ http://www.sovergs.com.br/site/38conbravet/res umos/886.pdf>, acessado em: 30 ago. 2013.

GARCIA-NAVARRO, C.E.K. Manual de urinálise veterinária. São Paulo: Varela, 2005. 95p.

GUIMARÃES, J.A.; DANTAS, A.C.; CAMARA, A.C.L. et al. Achados clínicos e bioquímicos (uréia e creatinina) na urolitíase obstrutiva em ovinos. Arch. Vet. Sci., v.12, Supl., p.127-129. 2007. 
GUIMARÃES, J.A.; MENDONÇA, C.L.; GUARANÁ, E.L.S. et al. Estudo retrospectivo de 66 casos de urolitíase obstrutiva em ovinos. Pesqui. Vet. Bras., v.32, p.824-830. 2012.

KANEKO, J.J.; HARVEY, J.W.; BRUSS, M.L. Clinical biochemistry of domestic animals. 6.ed. San Diego: Academic, 2008. 916p.

LAS, J. E.; ODONGO, N. E.; LINDINGER, M. I.; ALZAHAL, O.; SHOVELLER, A. K.; MATTHEWS, J. C.; MCBRIDE, B. W. Effects of dietary strong acid anion challenge on regulation of acid-base balance in sheep. J. Anim. Sci. v. 85, p. 2222-2229, 2007. MILOVSKY, A.V.; KONONOV, O.V. Mineralogy. Moscow: Mir Publishers, 1985. 320p.

MORAIS M.V. Estudo clínico-epidemiológico da urolitíase obstrutiva em caprinos e ovinos. 2012. 60f. Dissertação (Mestrado em Ciência Veterinária) - Departamento de Medicina Veterinária, Universidade Federal Rural de Pernambuco, Recife, PE. Disponível em: $<$ http://200.17.137.108/tde_busca/arquivo.php?c odArquivo $=1468>$. Acessado em: 22 Fev. 2013.

PRODUÇÃO DA PECUÁRIA MUNICIPAL. [Rio de Janeiro]: IBGE, 2010. 61p. Disponível em:

$<$ http://www.ibge.gov.br/home/estatistica/econo mia/ppm/2010/ppm2010.pdf >. Acessado em: 13 jun. 2014.

RADOSTITS, O.M.; GAY, C.C.; HINCHCLIFF, K.W.; CONSTABLE, P.D. Veterinary medicine: a textbook of the diseases of cattle, horses, sheep, pigs and goats. 10.ed. Edinbourg: Saunders, 2007. 2156 p.

RIET-CORREA, F. Suplementação mineral em pequenos ruminantes no semi-árido. Ciênc. Vet. Tróp., v.7, p.112-130, 2004.

RIET-CORREA, F.; SIMÕES, S.D.V.; VASCONCELOS, J.S. Urolitíase em caprinos e ovinos. Pesqui. Vet. Bras. v.28, p.319-322, 2008.
ROSENBERGER, G. Sistema urinário. In: ROSENBERGER. Exame clínico dos bovinos. 2.ed. Rio de Janeiro: Guanabara Koogan, 1983. p.252-266.

SILVA, E.R. Urolitiase em pequenos ruminantes. Rev. Bras. Med. Vet., v.19, p.144147, 1997.

SMITH M. C.; SHERMAN, D.M. Goat medicine. 2.ed. Ames: Wiley-Blackwell, 2009. $869 \mathrm{p}$.

SWENSON, M.J.; REECE, W.O. (Eds.). Dukes fisiologia dos animais domésticos. Rio de Janeiro: Guanabara Koogan, 1996. 856p.

TAKAGI, H.; BLOCK, E. Effects of manipulating dietary cation-anion balance on macromineral balance in sheep. J. Dairy Sci., v.74, p.4202-4214, 1991.

VALENCIANO, A.C.; COWELL, R.L. Diagnostic cytology and hematology of the dog and cat. 4.ed. St. Louis: Elsevier, 2014. p 402430 .

VAN METRE, D.C.; DIVERS, T.J. Urolitíase. In: SMITH, B.P. (Ed.). Medicina interna de grandes animais. 2.ed. São Paulo: Manole, 2006. p.853-860.

VINODHKUMAR, O.R.; SWARNKAR, C.P.; SHINDE, A.K.; SINGH, D. Clinical, mineral and haemato-biochemical studies of urolithiasis in wearner lambs. Afr. J. Agric. Res. v.5, p.20452050, 2010.

ZEN, S.D.; SANTOS, M.C.; MONTEIRO, C.M. Evolução da caprino e ovinocultura: ativos da pecuária de caprino e ovinocultura. 2014. 3p. Disponível em: $<$ http://www.canaldoprodutor.com.br/sites/defaul t/files/ativos_ovcapr_01_0.pdf $>$. Acessado em: 10 out. 2014 . 